JURNAL KEBIDANAN

Vol 6, No 3, Juli 2020 : 368-375

\title{
PENGETAHUAN IBU NIFAS MENGENAI PENYEMBUHAN LUKA PERINEUM DENGAN MENGGUNAKAN MEDIA BOOKLET
}

\author{
Millatina Ghassani ${ }^{1}$, Neneng Martini ${ }^{2}$, Ari Indra Susanti ${ }^{3}$, Sefita Aryuti Nirmala ${ }^{4}$, \\ Dini Saraswati Handayani ${ }^{5}$
}

\author{
${ }^{1}$ Program Pendidikan Diploma IV Kebidanan Fakultas Kedokteran, Universitas Padjadjaran \\ email: milltinaghassani97@gmail.com \\ ${ }^{2}$ Departemen IImu Kesehatan Masyarakat, Fakultas Kedokteran, Universitas Padjadjaran \\ email: Neneng_martini@yahoo.co.id \\ ${ }^{3}$ Departemen IImu Kesehatan Masyarakat, Fakultas Kedokteran, Universitas Padjadjaran \\ email: ari.indra@unpad.ac.id \\ ${ }^{4}$ Departemen IImu Kesehatan Masyarakat, Fakultas Kedokteran, Universitas Padjadjaran \\ email: Sefita@unpad.ac.id \\ 5Departemen IImu Kesehatan Masyarakat, Fakultas Kedokteran, Universitas Padjadjaran \\ email: d_zsharaswaty@yahoo.com
}

\begin{abstract}
Introduction: The Maternal Mortality Rate (MMR) in Indonesia occurs on postpartum due to bleeding and infection which is one of the causes is by perineal wound. Efforts to prevent infection from perineal wounds are necessary to increase maternal knowledge by providing health education using booklet media.

Pupose: This research aims to determine the effect of booklet media on knowledge of perineal wound healing in postpartum mothers in Sumedang Regional General Hospital.

Method: This research uses Quasy Experiment method with non randomized control group pretest posttest design approach. The writer collects samples with Consecutive Sampling techniques. This research was conducted in July 2019 to 80 postpartum mothers in Sumedang Regional General Hospital. The study subjects consisted of 40 postpartum mothers in the experimental group and 40 postpartum mothers in the control group. The technique used to collect the data is questionnaire. The experimental group is given with lecture method and booklet media. The control group is given with only lecture method. The bivariate data analysis uses Paired TTest processed by Statistical Package for Social Sciences (SPSS) program.

Results: The results of the research show that there is an increase in the knowledge of postpartum mothers before and after the media booklet is given $(p=0.000)$ so that there get an influence from giving it to the knowledge of postpartum mothers in Sumedang Regional General Hospital ( $r=0.378)$.

Conclusion: In this research, there is an influence from giving booklet media towards the knowledge of postpartum mothers about perineal wound healing in Sumedang Regional General Hospital.

Suggestion For postpartum mothers who have perineal lacerations it is advisable to pay more attention to the factors that can affect wound healing in the perineum so that the healing process can run well and the mother does not experience infection. Mothers who have perineal lacerations so as not to get infections, can pay attention to nutrition that must be consumed, mobility and how to care for wounds that are good and right
\end{abstract}

Keywords: Booklet media, perineal wound healing, the knowledge of postpartum mothers.

\section{ABSTRAK}

Latar Belakang: Angka Kematian Ibu (AKI) di Indonesia sebesar 40\% terjadi pada masa nifas akibat perdarahan dan infeksi, yang salah satunya disebabkan oleh luka perineum. Upaya untuk mencegah terjadinya infeksi dari luka perineum maka diperlukan upaya peningkatan pengetahuan ibu dengan memberikan pendidikan kesehatan menggunakan media booklet.

Tujuan: Penelitian ini bertujuan untuk mengetahui pengaruh media booklet terhadap pengetahuan mengenai penyembuhan luka perineum pada ibu nifas di RSUD Sumedang.

Metode: Penelitian ini menggunakan metode Quasy Experiment dengan pendekatan non randomized control group pretest posttest design. Pengambilan sampel menggunakan teknik Counsecutive Sampling. Penelitian ini dilaksanakan pada bulan Juli 2019 pada ibu nifas sebanyak 80 orang di RSUD Sumedang. subjek penelitian terdiri dari 40 ibu nifas pada kelompok experiment dan 40 ibu nifas pada kelompok control. 
Pengumpulan data dilakukan dengan menggunakan kuesioner. Kelompok experiment diberikan metode ceramah dan media booklet. Kelompok control diberikan metode ceramah saja. Analisis data bivariate menggunakan uji Paired T-Test yang diolah dengan program program Statistic Package for Sosial Sciene (SPSS).

Hasil: Hasil penelitian menunjukan bahwa terdapat peningkatan pengetahuan ibu nifas sebelum dan sesudah diberikan media booklet $(p=0,000)$ sehingga didapatkan pengaruh dari pemberian media booklet terhadap pengetahuan ibu nifas di RSUD Sumedang $(r=0,378)$.

Kesimpulan: Pada penelitian ini terdapat pengaruh dari pemberian media booklet terhadap pengetahuan ibu nifas mengenai penyembuhan luka perineum di RSUD Sumedang.

Saran Bagi ibu nifas yang memiliki luka robekan perineum disarankan agar lebih memperhatikan faktorfaktor yang dapat mempengaruhi penyembuhan luka pada perineum agar dalam proses penyembuhannya dapat berjalan dengan baik dan ibu tidak mengalami infeksi. Ibu yang memiliki luka robekan perineum agar tidak mengalami infeksi, dapat memperhatikan nutrisi yang harus di konsumsi, mobilitas dan cara perawatan luka yang baik dan benar

Kata Kunci: Media booklet, penyembuhan luka perineum, pengetahuan lbu nifas.

\section{PENDAHULUAN}

Masa nifas merupakan masa yang di mulai sejak seorang ibu melahirkan atau setelah plasenta lahir dan berakhir ketika alat-alat kandung kembali normal seperti semula keadaan ini dapat berlangsung hingga 42 hari. Komplikasi yang dapat terjadi pada masa nifas seperti retensio uteri, atonia uteri, ataupun luka robekan pada perineum (Primadona P \& Susilowati, 2015).

Menurut World Health Organization (WHO) hampir $90 \%$ proses persalinan normal mengalami robekan perineum baik dengan atau tanpa episiotomi. Di seluruh dunia robekan perineum terjadi sebanyak 2,7 juta kasus pada ibu bersalin. Angka ini masih akan terus meningkat hingga 6,3 juta di tahun 2020 jika tidak mendapat perhatian dan penanganan yang baik. Di negara Asia angka kejadian luka robekan perineum menjadi masalah yang cukup tinggi dalam masyarakat $50 \%$ di Dunia terjadi di negara Asia. Angka kejadian luka robekan perineum di Indonesia pada tahun 2014 mencapai $67,2 \%$ meningkat dari tahun sebelumnya yaitu $60 \%$ (WHO, 2014).

Di negara Indonesia lbu yang mengalami robekan perineum terjadi pada golongan usia 20-35 tahun $24 \%$ dan pada usia $32-39$ tahun $62 \%$. Hal ini diperkuat dengan hasil studi dari Pusat Penelitian dan Pengembangan (PUSLITBANG) Bandung, yang melakukan penelitian pada beberapa provinsi di Indonesia didapatkan 1 dari 5000 ibu bersalin yang mnegalmi robekan perineum akan meninggal dunia dengan proporsi 21,74\% (Intiyani R, Asturi DP \& Sofiana J, 2019). Robekan perienum terjadi sebanyak $85 \%$. Dari $85 \%$ ibu bersalin mengalami luka perineum terbagi menjadi $35 \%$ mengalami robekan perineum, $25 \%$ robekan serviks, $22 \%$ robekan vagina dan $3 \%$ robekan uretra. Di RSUD Sumedang setelah dilakukan observasi pada 3 bulan terakhir di tahun 2018 terjadi sekitar $60 \%$ robekan perienum pada ibu nifas dengan persalinan normal (Syamsiah S \& Malinda R, 2018).

Robekan perineum merupakan luka pada daerah muscular yang di tutupi kulit antar introitus vagina dengan anus yang disebabkan oleh robekan pada saat persalinan. Pada persalinan normal robekan yang terjadi dapat disebabkan karena pengeluaran kepala yang mendadak dan cepat, ukuran bayi yang berlebih, dan jaringan ibu yang mudah robek. Robekan dapat juga sebabkan oleh persalinan dengan porseps atau vakum ekstraksi (Prawitasari E, Yugistyanowati, \& Sari, 2015).

Luka perineum akan sembuh dalam waktu 7 hari, jika dalam satu minggu luka belum membaik ibu dapat mengalami infeksi. Faktor yang dapat memengaruhi penyembuhan luka perineum pada ibu nifas diantaranya yaitu mobilisasi dini, nutrisi atau pola makan dan cara perawatan luka dan faktor tambahan seperti senam nifas (Handayani E, Mundarti M, \& Sofiah, 2015).

Ibu nifas membutuhkan pengetahuan mengenai penyembuhan luka perineum, untuk menurunkan angka morbiditas dan mortalitas. Menurut penelitian yang dilakukan oleh Yayat Suryati pada tahun 2013 mengatakan bahwa pengetahuan ibu nifas mengenai penyembuhan luka perineum harus diajarkan dan ditanamkan pertama kali oleh tenaga kesehatan. Seorang tenaga kesehatan dapat menggunakan media dalam proses pemberian pendidikan kesehatan. Media dapat membantu proses pemberian pendidikan kesehatan sehingga pesan yang di sampaikan kepada ibu dapat dengan mudah diterima (Suryati, Kusyati, \& Hastuti, 2013). Menurut Dale, penangkapan pengetahuan yang diberikan melalui indera penglihatan, indera pendengaran dan 
indera lainnyac (Bagaray, Wowor, \& Mintjelungan, 2016).

Menurut A Wawan dan Dewi M tahun 2010 proses pengetahuan masuk kedalam otak manusia yaitu $10 \%$ dari hal-hal yang di baca, $30 \%$ yang di dengar, dan $20 \%$ yang di lihat. Pemberian pendidikan kesehatan dengan metode ceramah dan ditambah dengan pemberian media cetak seperti booklet dianggap memiliki tingkat pengetahuan yang lebih tinggi masuk kedalam otak ibu nifas yaitu sebesar 60\% (A Wawan, 2010).

Pengetahuan pada seseorang dapat dipengaruhi oleh berbagai faktor diantaranya faktor internal seperti usia, pendidikan, pekerjaan dan faktor eksternal yang didapatkan oleh ibu nifas melalui pendidikan non formal, seperti lingkungkan dan pengalaman yang menjadi faktor ibu nifas memiliki pengetahuan yang lebih baik. Faktor lain seperti media informasi yang di dapatkan oleh ibu dalam meningkatkan pengetahuan (Yanti, \& Handayani, 2014).

Booklet merupakan bentuk media yang dapat digunakan dalam proses pemberian pendidikan kesehatan. Booklet bertujuan untuk menyampaikan pesan atau informasi mengenai larangan, atau anjuran promisi kesehatan dalam bentuk buku dan berisikan gambar. Media booklet memiliki kelebihan diantaranya dapat dipelajari secara mandiri oleh ibu nifas, pesan atau informasi relatif lebih banyak dibanding media lain dan desain booklet yang menarik membuat ibu nifas tertarik untuk membacanya (Puspita, Kurniawan, \& Rahayu, 2017).

Penelitian lain juga dilakukan oleh Friza pada tahun 2016 di Desa Sukoharto mengatakan bahwa pendidikan kesehatan yang diberikan dengan menggunakan media booklet lebih menarik bagi responden sehingga lebih mudah dalam memahami materi yang terkandung didalamnya dan penelitian berbeda dilakukan oleh Naziah pada tahun 2018 mengatakan bahwa skor tingkat pengetahuan pendidikan kesehatan dengan media booklet lebih tinggi dibandingkan dengan sebelum perlakuan (Naziah, Nuraini, \& Zainaro, 2016).

Berdasarkan hal yang telah dikemukakan di atas, dan melalui observasi di lapangan dengan banyaknya angka kejadian robekan perineum di RSUD Sumedang, maka penulis tertarik untuk melakukan penelitian mengenai pengaruh media booklet terhadap pengetahuan penyembuhan luka perineum pada ibu nifas di RSUD Sumedang tahun 2019.

\section{METODOLOGI PENELITIAN}

Penelitian ini menggunakan metode Quasi Experiment dengan pendekatan yang digunakan adalah Non Randomized Control Group Pretest Postest Design. Penelitian ini dilaksanakan di RSUD Sumedang mulai tanggal 9 Juli 2019 hingga tanggal 23 Juli 2019. Populasi penelitian ini adalah seluruh ibu nifas di Ruang Dahlia RSUD Sumedang. Penelitian ini menggunakan metode pengumpulan sampel consecutive sampling. Total sampel yang digunakan 80 orang, yang dibagi menjadi 40 orang pada masng-masing kelompok. Sampel tersebut akan diseleksi berdasarkan kriteria inklusi, yaitu ibu nifas yang bersedia mengikuti penelitian dengan menandatangani lembar informedconsent, ibu nifas yang memiliki luka robekan perineum, ibu nifas yang tidak buta huruf serta ibu nifas atau keluiarga yang memiliki nomer telfon atau WhatsApp yang dapat dihubungi. Data penelitian ini diperoleh menggunakan kuesioner. Kuesioner akan diberikan pada saat pre-test dan post-test, pertanyaan diberikan secara tertulis dan melalui Google form. Analisa data menggunakan analisa univariat disajikan dalam bentuk tabel distribusi frekuensi dan bivariat dengan uji statistik paired T-Test. Sebelumnya, data penelitian ini dilakukan uji normalitas terlebih dahulu dengan menggunakan uji kolmogorov-smirnov dengan hasil uji data berdistribusi normal. Data diolah dengan komputerisasi menggunakan program Microsoft Excel 2013 dan SPSS.

\section{HASIL PENELITIAN \\ Analisis univariat}

Berdasarkan tabel 1 dapat diketahui bahwa sebagian besar responden berusia 20-35 tahun, pada kelompok experiment yaitu sebanyak $67,5 \%$ dan pada kelompok control yaitu sebanyak $65,0 \%$. Pendidikan terakhir yang ditempuh oleh responden pada kelompok experiment sebagian besar hingga SMA/SMU/SMK yaitu sebanyak $55,0 \%$ dan pada kelompok control sebangian besar hingga SMP/SLTP yaitu sebanyak $42,5 \%$. Pada kedua kelompok pekerjaan terbanyak yaitu tidak bekerja/IRT sebesar 95,0\%. Status paritas responden pada kelompok experiment sebagian besar terjadi pada ibu primipara dan multipara yaitu sebanyak 47,5\% dan pada kelompok control sebagian besar terjadi pada ibu primipara yaitu sebanyak $57,3 \%$. 
Tabel 1.

Distribusi Frekuensi Karakterisitik Ibu Nifas

\begin{tabular}{lcccc}
\hline \multirow{2}{*}{$\begin{array}{l}\text { Karakteristik } \\
\text { Ibu Nifas }\end{array}$} & \multicolumn{4}{c}{ Kelompok } \\
\cline { 2 - 5 } & $(\mathrm{f})$ & $(\%)$ & $(\mathrm{f})$ & $(\%)$ \\
\hline Usia & 5 & 12,5 & 5 & 12,5 \\
$<20$ tahun & 27 & 67,5 & 26 & 65,0 \\
20-35 tahun & 8 & 20,0 & 9 & 22,5 \\
$>35$ tahun & & & & \\
Pendidikan & 4 & 10,0 & 7 & 17,5 \\
SD & 8 & 20,0 & 17 & 42,5 \\
SMP/SLTP & 22 & 55,0 & 14 & 35,0 \\
SMA/SMU/SMK & 1 & 2,5 & 0 & 0 \\
Diploma & 5 & 12,5 & 2 & 5,0 \\
Sarjana & & & & \\
Pekerjaan & 2 & 5,0 & 2 & 5,0 \\
Berkerja & 38 & 95,0 & 38 & 95,0 \\
Tidak Berkerja/IRT & & & & \\
Paritas & 0 & 0 & 0 & 0 \\
Nulipara & 19 & 47,5 & 23 & 57,5 \\
Primipara & 19 & 47,5 & 14 & 35,0 \\
Multipara & 2 & 5,0 & 3 & 7,5 \\
Grandemultipara & 40 & $100 \%$ & 40 & $100 \%$ \\
\hline$\quad$ Total & & & & \\
\hline
\end{tabular}

Tabel 2.

Pengetahuan Ibu Nifas pada Kelompok Experiment dan Control

\begin{tabular}{ccccc}
\hline \multirow{3}{*}{ Skor Pengetahuan } & \multicolumn{4}{c}{ Kelompok } \\
\cline { 2 - 5 } & \multicolumn{2}{c}{ Experiment } & \multicolumn{2}{c}{ Control } \\
\cline { 2 - 5 } & Pre-Test & Post-Test & Pre-Test & Post-Test \\
\hline Mean (SD) & $17,18(3,43)$ & $21,98(2,15)$ & $17,03(3,10)$ & $18,80(3,01)$ \\
Median & 18,00 & 22,00 & 17,00 & 19,00 \\
Rentang & $4-22$ & $18-25$ & $10-22$ & $7-24$ \\
Perbedaan & \multicolumn{2}{c}{$p 0,000$} & \multicolumn{2}{c}{$p 0,004$} \\
\% Peningkatan & \multicolumn{2}{c}{10,4} \\
\hline
\end{tabular}

Berdasarkan tabel 2 dapat diketahui bahwa terdapat perbedaan nilai mean pada kedua kelompok antara pre-test dan post-test. Pada kelompok experiment nilai mean 17,18 dengan standar deviasi 3,43 menjadi 21,98 dengan standar deviasi 2,15 dan kelompok control 17,03 dengan standar deviasi 3,10 menjadi 18,80 dengan standar deviasi 3,01, dan nilai median kelompok experiment 18,00 menjadi 22,00 kelompok control 17,00 menjadi 19,00 . Perbedaan rentang antara pre-test dan post-test pada kelompok experiment 4-22 menjadi 18-25 pada kelompok control 10-22 menjadi $7-24$, dengan nilai $p$-value pada kedua kelompok $p<0,05$, dan diketahui bahwa pada kelompok experiment memiliki peningkatan skor pengetahuan $28 \%$, sedangkan pada kelompok control peningkatan skor pengetahuan $10,4 \%$.

\section{Analisis bivariat}

Berdasarkan tabel 3 dapat diketahui bahwa terdapat pengaruh pemberian booklet terhadap peningkatan pengetahuan ibu nifas pada kelompk experiment antara pre-test dan post-test dengan nilai $p=0,000(p<0,05)$, namun memiliki tingkat pengaruh yang rendah dengan nilai $r=0,378$. 
Tabel 3.

Pengaruh Pemberian Booklet terhadap Pengetahuan Ibu Nifas

\begin{tabular}{cccccc}
\hline \multirow{2}{*}{ Pengetahuan } & $\mathrm{N}$ & Median (min-max) & Mean \pm SD & $P$-Value & $r$ \\
\cline { 2 - 6 } & 40 & 18,00 & $17,18 \pm 3,434$ & 0,000 & 0,378 \\
Pre-Test & 40 & 22,00 & $21,98 \pm 2,154$ & & 0, Post-Test \\
\hline
\end{tabular}

\section{PEMBAHASAN}

\section{Karakteristik Ibu Nifas}

Penelitian ini menunjukan bahwa responden tergolong dalam usia produktif yaitu 20-35 tahun memiliki frekuensi terbanyak sebesar $67,5 \%$ dan $65 \%$ pada masing-masing kelompok. Menurut Wiknjosastro, usia 20-35 tahun merupakan usia produktif dan usia yang tepat bagi seorang wanita untuk hamil, karena tubuh dalam keadaan yang sehat dan aman untuk hamil dan melahirkan. Menurut Muchtar, meskipun usia ibu normal atau dalam usia produktif apabila jarang berolahraga seperti senam kegel atau senam hamil dan rajin berhubungan suami istri saat sebelum hamil, ibu dapat mengalami robekan pada perineum. Selain itu juga, kelenturan pada jalan lahir dapat berkurang apabila ibu jarang berolahraga dan pada daerah genetalia sering terkena infeksi (Suparti, 2019).

Berdasarkan hasil penelitian ini, responden dengan tingkat pendidikan SMA/SMU/SMK memiliki frekuensi terbanyak yaitu sebesar $55 \%$ dan SMP/SLTP sebesar 42,5\%. Menurut teori terdapat 2 faktor yang dapat memengaruhi pengetahuan seseorang yaitu faktor internal dan faktor eksternal. Faktor internal seperti seperti pendidikan, pekerjaan, usia, dan media informasi. Faktor eksternal seperti lingkungan dan status budaya (Yanti, \& Handayani, 2014). Dalam penelitian ini artinya pengetahuan yang di dapatkan oleh ibu nifas mengenai penyembuhan luka perineum didapatkan dari faktor eksternal. Dimana sebagian ibu nifas mengatakan sudah mengetahui bagaimana cara memenuhi kebutuhan nutrisi dan cara merawat luka perineum dari keluarga ataupun teman. Lingkungan akan sangat berpengaruh terhadap peningkatan pengetahuan, ibu nifas akan menerima informasi yang dibutuhkan sehingga, melalui lingkungan ibu nifas dapat memperoleh pengalaman dan pengetahuan, baik secara langsung maupun tidak langsung.

Selain tingkat pendidikan, pengetahuan dipengaruhi oleh pekerjaan. Pada penelitian ini, responden dengan status pekerjaan sebagai ibu rumah tangga memiliki frekuensi terbanyak yaitu sebesar 95\% pada masing-masing kelompok. Pekerjaan merupakan kegiatan yang dilakukan oleh seseorang dan mendapatkan pengahsialan atau upah (A Wawan, 2010). Menurut Notoatmodjo seseorang yang bekerja, akan mempunyai banyak informasi dan pengalaman. Status pekerjaan akan berpengaruh terhadap peningkatan pengetahuan seseorang yang akhirnya akan berdampak pada pengetahuan. Hal ini sejalan dengan penelitian yang dilakukan oleh Titik Anggraeni mengenai hubungan pengetahuan dan pekerjaan ibu dengan pemberian ASI ekslusif, sebanyak 27 (62,8\%) menjadi ibu rumah tangga, Titik mengatakan bahwa pekerjaan dapat mempengaruhi perilaku seseorang dan pekerjaan dapat menjadi penggambaran kedudukan sosial dan kemampuan ekonomi yang dimiliki oleh seseorang (Anggraeni, 2016).

Robekan perineum yang terjadi pada ibu dapat disebabkan oleh status paritas. Hasil dalam penelitian ini, responden dengan status paritas primipara memiliki presentase terbanyak yaitu sebesar $47,5 \%$ dan $57,5 \%$ pada masing-masing kelompok serta $47,5 \%$ terjadi pada ibu dengan status multipara. Status primipara biasanya memiliki perineum lebih kaku sehingga rentan terjadi robekan. Perineum yang kaku kemungkinan besar tidak dapat beradaptasi terhadap regangan yang berlebih sehingga dapat mengakibatkan robekan perineum. Selain itu, umumnya ibu belum memiliki pengalaman dalam melahirkan sebelumnya, ibu belum mengetahui seperti teknik mengejan yang benar, posisi persalinan yang benar dan kurangnya informasi yang diberikan pada ibu selama masa hamil mengenai pencegahan robekan perineum. Namun, tidak menutup kemungkinan ibu dengan multipara dan grandemultipara dapat mengalami ruptur perineum. Hal tersebut, terjadi karena setiap orang memiliki tingkat keelastisan perineum yang berbeda (Elisa, \& Yuniarti, 2016).

Penelitian ini sejalan dengan penelitian yang dilakukan oleh Puspito Panggih mengenai faktor yang berhubungan dengan kejadian ruptur perineum mengatakan bahwa terdapat hubungan antara paritas dengan ruptur perineum dimana pada ibu dengan status paritas primipara dan multipara memiliki peluang 3 kali lebih besar mengalami ruptur dibandingkan dengan ibu berstatus paritas grandemultipara pada umumnya (Rahayu, 2016). 


\section{Pengetahuan Ibu Nifas}

Berdasarkan tabel 2 menunjukan hasil penelitian bahwa terdapat peningkatan pengetahuan pada kelompok experiment $28 \%$ dan pada kelompok control terjadi peningkatan sebesar 10,4\%. Perbedaan kenaikan pada kedua kelompok menunjukan hasil yang bermakna sehingga pemberian pendidikan kesehatan melalui metode ceramah dengan atau tanpa media booklet dapat dikatakan sama karena keduanya memiliki skor peningkatan. Namun, dalam penelitian ini menunjukkan bahwa peningkatan skor pengetahuan pada kelompok experiment lebih tinggi dibandingkan kelompok control. Sejalan dengan penelitian yang dilakukan oleh Yessie mengenai efektifitas penggunaan media booklet terhadap peningkatan pengetahuan gizi seimbang ibu balita menyatakan bahwa selisih rata-rata peningkatan pengetahuan kelompok experiment adalah 4,8 sehingga, kelompok experiment memiliki tingkat pengetahuan lebih tinggi dibandingkan dengan kelompok control (Pratiwi, \& Puspitasari, 2017).

Pengetahuan merupakan hasil tahu yang terjadi pada ibu nifas setelah mengadakan indra penglihatan dan pendengaran terhadap pendidikan kesehatan dengan media booklet dan metode ceramah yang diberikan mengenai penyembuhan luka perineum.

Menurut Budioro, proses pengetahuan masuk dalam otak manusia yaitu $10 \%$ dari hal-hal yang di baca, $30 \%$ dari hal-hal yang di dengar dan $20 \%$ dari hal-hal yang di lihat. Hal ini menunjukan bahwa ibu nifas yang menerima pendidikan kesehatan dengan metode ceramah dan media booklet mengenai penyembuhan luka perineum dianggap memiliki pengetahuan lebih tinggi yaitu sebesar $60 \%$ masuk kedalam otak dibandingkan dengan ibu nifas yang menerima pendidikan kesehatan dengan metode ceramah saja yaitu hanya 30\% (A Wawan, 2010).

Seseorang memiliki 7 tingkatan pengetahuan ibu nifas telah melalui fase tahu (know) dimana dalam tingkatan ini tahu merupakan cara mengingat suatu materi yang telah dipelajari sebelumnya, termasuk pengetahuan mengingat kembali (recall) dari sesuatu yang telah dipelajari atau diketahui. Ibu nifas akan mencoba untuk mengingat kembali materi yang telah disampaikan melalui metode ceramah dan akan di ukur tingkatan pengetahuan melalui pre-test. Lalu, tingkatan selanjutnya yaitu memahami (comprehension) dimana ini merupakan suatu kemampuan untuk menjelaskan kembali secara benar mengenai objek yang telah diketahui dan dapat menginterpretasikan materi tersebut dengan benar, pada tingkatan ini dapat diukur dengan melihat hasil post-test pada ibu nifas (Yanti, \& Handayani, 2014).

Faktor-faktor yang memengaruhi peningkatan pengetahuan pada ibu nifas dalam penelitian ini selain dari faktor internal seperti pendidikan, pekerjaan, usia, atau faktor ekternal seperti lingkungan dan status budaya, adapun faktor internal lain seperi media informasi. Media informasi memiliki pengaruh besar terhadap pengetahuan seseorang. Informasi yang diberikan dapat secara formal maupun non formal, keduanya akan mempengaruhi pengetahuan dan dapat menghasilkan perubahan atau peningkatan pengetahuan seseorang (Listyaningrum, \& Vidayanti, 2016).

Menurut Keeley dalam Spreger menunjukkan bahwa lama interval akan memengaruhi kekuatan retensi. Keeley menyatakan $54 \%$ materi akan diingat setelah 1 hari, 35\% setelah 7 hari, 21\% setelah 14 hari dan $8 \%$ setelah 21 hari. Hal ini berarti bahwa ibu nifas yang sudah membaca booklet dan menerima pendidikan kesehatan melalui metode ceramah setelah 24 jam dapat mengingat materi hingga $54 \%$. Sehingga, dalam pemberian post-test pada kelompok experiment memiliki perubahan terhadap peningkatan pengetahuan hal ini terjadi karena daya ingat ibu lebih tinggi mengenai materi yang di sampaikan (Puspitaningrum, Agusyahbana, Mawarni, \& Nugroho, 2017).

\section{Pengaruh Media Booklet terhadap Pengetahuan}

Hasil uji Paired T-Test diperoleh nilai $p$-value sebesar 0,000 dan besar nilai $r 0,378$ artinya secara statistik menunjukkan terdapat perbedaan pengetahuan ibu nifas sebelum dan sesudah diberikan media booklet. Sehingga dapat disimpulkan bahwa pemberikan pendidikan kesehatan melalui metode ceramah dan media booklet memberikan pengaruh yang cukup signifikan terhadap peningkatan pengetahuan ibu nifas mengenai penyembuhan luka perineum.

Hasil penelitian ini tidak bisa dibandingkan dengan penelitian lain karena sejauh ini belum terdapat penelitian yang melihat pengaruh pemberian media booklet terhadap pengetahuan penyembuhan luka perineum pada ibu nifas. Namun demikian, terdapat penelitian-penelitian serupa lain yang sejalan dengan penelitian ini. Hasil penelitian ini sejalan dengan penelitian yang dilakukan oleh Yessie Finandita mengenai efektifitas penggunaan media booklet terhadap pengetahuan gizi seimbang pada ibu balita yang menyebutkan bahwa kedua kelompok dalam 
penelitiannya memiliki tingkatan yang sama, meskipun nilai rata-rata pada kelompok experiment lebih tinggi dibandingkan kelompok kontrol sehingga tingkat pengetahuan ibu yang diberikan metode ceramah menggunakan media booklet lebih tinggi dibandingkan ibu yang diberikan metode ceramah saja. Penilitian yang dilakukan oleh Yessie menunjukan hasil bahwa terdapat perbedaan yang signifikan $(p<0,000)$ pada hasil pre-test dan posttest setelah pemberian media booklet terhadap pengetahuan gizi seimbang pada ibu balita (Pratiwi, \& Puspitasari, 2017).

Pemberian media booklet dalam penelitian ini tidak memiliki pengaruh yang cukup tinggi terhadap pengetahuan ibu nifas mengenai penyembuhan luka perineum. Hal ini terjadi karena adanya faktor lain seperti ibu nifas yang sudah memiliki pengetahuan mengenai penyembuhan luka perineum melalui metode ceramah oleh tenaga kesehatan, ibu nifas yang sudah mengetahui cara perawatan luka perineum dari keluarga ataupun teman sekitar yang dianggap memiliki pengalaman lebih banyak dan dari budaya setempat atau tradisi yang ada di masyarakat. Faktor ini dianggap sebagai faktor eksternal yang dapat memengaruhi pengetahuan ibu menjadi cukup baik (Yanti, \& Handayani, 2014). Faktor internal lain yang dapat memengaruhi pengetahuan ibu nifas di RSUD Sumedang antara lain adalah usia, karena banyak ibu nifas yang berusia 20-35 tahun. Usia menjadi salah satu faktor yang dapat memengaruhi pengetahuan karena semakin dewasa seseorang memiliki presentase pengetahuan semakin baik hal ini disebabkan karena akses informasi, dan wawasan yang lebih tinggi didapatkan pada usia produktif.

Tingginya tingkat pengetahuan ibu belum bisa merubah sikap dan perilaku ibu nifas dalam melakukan perawatan luka perineum ini dibuktikan dengan masih banyaknya kejadian infeksi luka jahitan perineum pada ibu. Maka dari itu, dengan pemberian media booklet ibu diharapkan bisa membaca, mengingat dan mempraktikannya sesuai dengan materi yang disampaikan (Listyaningrum, \& Vidayanti, 2016).

Isi dari booklet dalam penelitian ini merupakan gabungan dari gambar-gambar dan kalimat yang mudah dipahami oleh ibu nifas sehingga akan lebih mudah untuk ibu menerima informasi mengenai penyembuhan luka perineum yang disampaikan. Gambar yang menarik dan kalimat yang mudah di pahami dalam booklet akan menarik minat ibu untuk membaca dan fokus pada informasi yang disampaikan. Kelebihan dari penggunaan media cetak seperti booklet antara lain praktis dalam penggunaannya dapat dilakukan kapan saja, tidak menggunakan listrik dan booklet tidak hanya berisi tentang teks tetapi terdapat gambar sehingga menimbulkan rasa keindahan serta meningkatkan kepahaman dan gairah dalam belajar (Pratiwi, \& Puspitasri, 2017).

Menurut Nurseto pendidikan kesehatan dikenalkan dengan beberapa media pendidikan mulai dari yang sederhana sampai dengan yang canggih yang disesuiakan dengan kondisi dan situasi pemberian pendidikan kesehatan misalnya tempat, waktu, sasaran, kebutuhan, dan tujuan. Beberapa alat peraga yang bisa digunakan dalam pemberian pendidikan kesehatan diantaranya adalah papan tulis, Over Head Projector (OHP), kertas flipchart, poster, flash card, model, leaflet, benda asli, kartu, booklet, kaset, video-film, slide, dan media social (Nurseto, 2011).

\section{SIMPULAN}

Hasil penelitian menunjukan adanya pengaruh pemberian booklet terhadap peningkatan pengetahuan ibu nifas pada kelompk experiment antara pre-test dan post-test dengan nilai $p=0,000$ $(p<0,05)$, namun memiliki tingkat pengaruh yang rendah dengan nilai $r=0,378$.

\section{SARAN}

Bagi ibu nifas yang memiliki luka robekan perineum disarankan agar lebih memperhatikan faktor-faktor yang dapat mempengaruhi penyembuhan luka pada perineum agar dalam proses penyembuhannya dapat berjalan dengan baik dan ibu tidak mengalami infeksi. Ibu yang memiliki luka robekan perineum agar tidak mengalami infeksi, dapat memperhatikan nutrisi yang harus di konsumsi, mobilitas dan cara perawatan luka yang baik dan benar. Bagi rumah sakit disarankan pada tenaga kesehatan yang bertugas untuk melakukan tugasnya sesuai dengan standar asuhan persalinan normal dalam memberikan penanganan pada klien dan dalam memberikan pendidikan kesehatan tidak hanya menggunakan metode ceramah saja tetapi dapat menambahnya dengan menggunakan media cetak seperti booklet. Dimana booklet memiliki kelebihan seperti lebih menarik, rinci, ringkas, dapat disimpan dalam jangka waktu yang lama, dan dapat dipelajari secara mandiri. Sehingga, pengetahuan ibu nifas mengenai penyembuhan luka perineum akan meningkat dan tingkat infeksi luka perineum pada ibu nifas dapat menurun bahkan tidak ada yang mengalami infeksi di kemudian hari. Selain itu juga diharapkan pada penelitian selanjutnya dapat memperhatikan bagaimana cara pemberian informasi yang memiliki pengaruh lebih besar terhadap pengetahuan pada ibu nifas dengan 
menggunakan media informasi lain seperti melalui media elektronik, media masa, atau media cetak yang lainnya seperti buku saku, majalah, dan lain sebagainya.

\section{DAFTAR PUSTAKA}

Anggraeni, T. (2016). Hubungan Pengetahuan dan Pekerjaan Ibu dengan pemberian ASI eksklusif di Posyandu Lestari Handayani Desa Jembungan Kabupaten Boyolali. Jurnal INFOKES Universitas Duta Bangsa Surakarta, 6(1).

Bagaray, F. E., Wowor, V. N., \& Mintjelungan, C. N. (2016). Perbedaan efektivitas DHE dengan media booklet dan media flip chart terhadap peningkatan pengetahuan kesehatan gigi dan mulut siswa SDN 126 Manado. e-GiGi, 4(2).

Elisa, S. N. E., \& Yuniarti, S. (2016). Hubungan Paritas dengan Terjadinya Robekan Perineum Spontan pada Persalinan Normal. Jurnal Bidan, 2(2), 234050.

Handayani, E., Mundarti, M., \& Rofiah, S. (2015). Faktor yang Mempengaruhi Penyembuhan Luka Perineum Pada lbu Post Partum. LINK, 11(3), 1041-1047.

Intiyani, R., Astuti, D. P., \& Sofiana, J. (2019). PEMBERIAN SUPLEMENTASI ZINC DAN EKSTRAK IKAN GABUS UNTUK MEMPERCEPAT PENYEMBUHAN LUKA PERINEUM. Proceeding of The URECOL, 571-578.

Listyaningrum, T., \& Vidayanti, V. (2016). Tingkat Pengetahuan dan Motivasi Ibu Berhubungan dengan Pemberian ASI Eksklusif pada lbu Bekerja, 4(2), 55-62.

Naziah, N., Nuraini, N., \& Zainaro, M. (2018). Pengaruh Pendidikan Kesehatan Dengan Media Booklet Tentang Pencegahan Primer \& Sekunder Terhadap Pengetahuan Pasien Coronary Artery Disease (CAD) di Klinik Sehat Natural Ciledug Tanggerang Selatan Tahun 2016. Holistik Jurnal Kesehatan, 12(1), $10-20$.

Nurseto T. (2011). Membuat media pembelajaran yang menarik. Jurnal Ekonomi dan Pendidikan, 8(1).

Pratiwi, Y., \& Puspitasari, D. (2017). Efektivitas Penggunaan Media Booklet terhadap Pengetahuan Gizi Seimbang pada Ibu Balita Gizi Kurang di Kelurahan Semanggi Kecamatan Pasar Kliwon Kota Surakarta. Jurnal Kesehatan, 10(1), 58-67.

Prawitasari, E., Yugistyowati, A., \& Sari D. (2015). Penyebab Terjadinya Ruptur Perineum pada
Persalinan Normal di RSUD Muntilan Kabupaten Magelang, 3(2), 77-81.

Primadona, P., \& Susilowati, D. (2015). Penyembuhan Luka Perineum Fase Proliferasi Pada lbu Nifas. Profesi (Profesional Islam): Media Publikasi Penelitian, 13(1).

Puspita, A., Kurniawan, A., \& Rahayu, H. (2017). Pemngembangan Media Pembelajarab Booklet Pada Materi Sistem Imun Terhadap Hasil Belajar Siswa Kelas XI SMAN 8 Pontianak. Jurnal Bioeducation, 4(1).

Puspitaningrum, W., Agusyahbana, F., Mawarni, A., \& Nugroho, D. (2017). Pengaruh Media Booklet terhadap Pengetahuan dan Sikap Remaja Putri terkait Kebersihan dalam Menstruasi di Pondok Pesantren Al-Ishlah Demak Triwulan II tahun 2017. Jurnal Kesehatan Masyarakat (e-Journal), 5(4), 274-81.

Rahayu, P. (2016). Faktor Yang Berhubungan Dengan Kejadian Ruptur Perineum Di Puskesmas Mergangsan Kota Yogyakarta Tahun 2014. Medika Respati, 11(2).

Suparti, S. Hubungan Berat Badan Bayi Baru Lahir Terhadap Ruptur Perineum pada lbu Bersalin Di KPD" Sumber Waras" Sukerejo Kecamatan Musuk Boyolali Tahun 2018. Jurnal Kebidanan Indonesia: Journal of Indonesia Midwifery, 10(1), 147-57.

Suryati, Y., Kusyati, E., \& Hastuti, W. (2013) Hubungan Tingkat Pengetahuan Ibu Nifas Tentang Perawatan Luka Perineum Dan Status Gizi Dengan Proses Penyembuhan Luka, 1(1).

Syamsiah, S., \& Malinda, R. Determinan Kejadian Ruptur Perineum di BPM EN Surabaya. (2018). Jurnal IImiah Kesehatan, 10(2), 1908.

Wawan, A., \& Dewi, M. (2010). Teori dan pengukuran pengetahuan, sikap dan perilaku manusia. Yogyakarta: Nuha Medika, 11-18.

WHO. (2014). Angka Kematian lbu pada Tahun 2014. Bascometro;2014.

Yanti, G., \& Handayani, S. (2014). Hubungan Pengetahuan Dan Sikap Dengan Pelaksanaan Metode Amenorea Laktasi (MAL) Pada Ibu Nifas Di Wilayah Kerja Puskesmas Kecamatan Sukoharjo Lampung, 5(02).

Yulianti , S.,\& Wijayanti. (2016). Hubungan tingkat pendidikan dan tingkat pengetahuan tentang kesehatan jiwa dengan sikap masyarakat terhadap pasien gangguan jiwa di RW XX Desa Duwet Kidul, Baturetno, Wonogiri. Jurnal IImu Kesehatan Kosala, 4(1). 